\title{
Systematic evaluation of the impacts of GPSRO data on the prediction of typhoons over the northwestern Pacific in 2008-2010
}

\author{
Y.-C. Chen ${ }^{1}$, M.-E. Hsieh ${ }^{1}$, L.-F. Hsiao ${ }^{1}$, Y.-H. Kuo ${ }^{2}$, M.-J. Yang ${ }^{3}$, C.-Y. Huang ${ }^{4}$, and C.-S. Lee ${ }^{1}$ \\ ${ }^{1}$ Taiwan Typhoon and Flood Research Institute, National Applied Research Laboratories, Taipei, Taiwan \\ ${ }^{2}$ National Center for Atmospheric Research, Boulder, Colorado, USA \\ ${ }^{3}$ National Taiwan University, Department of Atmospheric Sciences, Taipei, Taiwan \\ ${ }^{4}$ National Central University, Department of Atmospheric Sciences, Jhongli, Taoyuan County, Taiwan \\ Correspondence to: Y.-C. Chen (cwb.xb14@gmail.com)
}

Received: 31 October 2014 - Published in Atmos. Meas. Tech. Discuss.: 29 January 2015

Revised: 08 May 2015 - Accepted: 15 May 2015 - Published: 23 June 2015

\begin{abstract}
In this paper, we perform a systematic evaluation of the impact of Global Positioning System radio occultation (GPSRO) data on typhoon-track prediction over the northwestern Pacific. Specifically, we perform data assimilation and forecast experiments using the Typhoon Weather Research and Forecasting (TWRF) system at $45 \mathrm{~km}$ resolution on 11 typhoons (with a total of 327 cases) in the period of 2008-2010 over the northwestern Pacific, with or without the use of GPSRO refractivity observations. On average, about 100 GPSRO soundings are assimilated over a $12 \mathrm{~h}$ partially cycling assimilation period. The results indicate that the assimilation of GPSRO data reduces the $72 \mathrm{~h}$ track forecast errors by approximately $12 \mathrm{~km}(5 \%)$. Although this is only a modest improvement, it is statistically significant. The assimilation of GPSRO data improves the analysis and the forecast of temperature, water vapor, and wind fields. Further analysis shows that the reduction in typhoon-track forecast errors can be attributed to the improved prediction of western Pacific subtropical high (WPSH) and its associated circulation, which leads to better forecasting of the environmental steering flow.
\end{abstract}

\section{Introduction}

Typhoons are the worst among the four major catastrophic natural disasters, which are responsible for significant loss in human lives and properties in the Taiwan area almost every year. However, the rainfall brought by typhoons is also the main source of water for the residents of the island in the summer. Therefore, the prediction of typhoons and their associated rainfall has always been one of the most difficult forecasting problems in Taiwan. Given the strong modulation of Taiwan's Central Mountain Range (CMR) on typhoon's wind and rainfall distributions, the greatest challenge for typhoon prediction is the forecast of typhoon track, which largely dictates the subsequent local wind and rainfall distributions. Taiwan is located on the climatological mean path for typhoons originating from the western North Pacific Ocean. The western Pacific subtropical high (WPSH) has a profound influence on the track of typhoons. The growth and decay of both the oceanic warm-core subtropical high over the western Pacific and continental cold-core Siberian high affect the position and movement of frontal systems in the vicinity of Taiwan. In addition, the circulation of WPSH affects not only the position of the East Asian summer monsoon trough but also the track of typhoons over the western North Pacific.

A successful forecast of a numerical model depends not only on the dynamics and physical processes of the model but also on the quality of the model initial condition. In particular, the latter can be improved through the assimilation of available observation. Since conventional radiosonde observations are mostly available only over land, there are very few in situ sounding data over the ocean, which makes it difficult to accurately analyze and predict the WPSH. The use of non-traditional sounding observations over the tropical ocean is very important.

Radio occultation (RO) is a limb sounding technique which tracks the radio signals transmitted from the satel- 
lites of the Global Navigation Satellite System (GNSS) by using receivers on board a low earth orbit (LEO) satellite. By measuring the changes in phase caused by the refraction of Earth's atmosphere on the electromagnetic wave, the bending angle of the rays and the refractivity of Earth's atmosphere are derived (Ware et al., 1996). With the advantage of high vertical resolution ( $\sim 10$ 's of $\mathrm{m}$ to $1 \mathrm{~km}$, from surface to stratosphere), global coverage, all-weather sensing (Kursinski et al., 1997), Global Positioning System (GPS) radio occultation data can complement conventional sounding data and microwave and infrared satellite observations.

Since the launch of GPS/MET (GPS Meteorology; Ware et al., 1996) in 1995, a proof-of-concept mission, the advantages of Global Positioning System radio occultation (GPSRO) measurement technique have been demonstrated (Kuo et al., 1997) by several subsequent missions, including the CHAllenging Minisatellite Payload (CHAMP) of Germany (Wickert et al., 2001), the Satellite de Aplicaciones Cientificas-C (SAC-C) of Argentine (Hajj et al., 2004), the joint Germany-US Gravity Recovery And Climate Experiment (GRACE) (Wickert et al., 2008), the TerraSAR-X of Germany (Wickert et al., 2008), and the Meteorological Operational (MetOp) satellites of European Organization for the Exploitation of Meteorological Satellites (EUMETSAT) (Larsen et al., 2004). The joint Taiwan-US FORMOSAT3/Constellation Observing System for Meteorology, Ionosphere, and Climate (COSMIC; Anthes et al., 2008) launched in 2006 is the first GPSRO mission with a constellation of six satellites, providing full global coverage. Since launch, COSMIC has been providing 1500-2500 GPSRO soundings per day in near real time, supporting operational numerical weather prediction around the world. All major operational centres have reported significant positive impacts from the assimilation of GPS RO data (Healy, 2008; Buontempo et al., 2008; Cucurull et al., 2007; Cucurull and Derber, 2008; Aparicio et al., 2009; Poli et al., 2010).

In recent years, several studies have assessed the impact of GPSRO observation on the prediction of tropical cyclones. Huang et al. (2005) used the MM5 3DVAR system to assimilate the GPSRO refractivity data from CHAMP and SAC$\mathrm{C}$ to investigate its impact on the forecast of Typhoon Nari (2001) and Nakri (2002). They showed that the assimilation of GPSRO improves the track and intensity forecast of Typhoon Nari. In the simulation of Typhoon Nakri, assimilating GPSRO observations reduces the rainfall over southeastern Taiwan, bringing it closer to the observed amount. Kueh et al. (2009) performed sensitivity tests for the simulation of Typhoon Bilis (2006) with only two COSMIC GPSRO soundings and found that the one to the east of the typhoon produced a significant positive impact on the track forecast. Kuo et al. (2009) assimilated the refractivity of COSMIC GPSRO with WRF-3DVAR and WRF-DART data assimilation systems and showed that the track forecast of Typhoon Shanshan (2006) was significantly improved. In particular, they showed that the ensemble Kalman filter data assimila- tion system was able to extract the information provided by GPSRO more effectively than the 3-D variational data assimilation system to improve typhoon prediction. More recently, Liu et al. (2012) showed that the assimilation of GPSRO refractivity was critical in capturing the genesis of Hurricane Ernesto (2006), by correcting the dry bias of model initial condition, which was based on the NCEP (National Centers for Environmental Prediction) global analysis.

Most previous researches investigating the impact of GPSRO observations on typhoon forecast are case studies. There are few systematic evaluations based on a large number of cases. Therefore, statistical significance of the impact of GPSRO on typhoon prediction has been lacking. Shen et al. (2011) assessed the impact of GPSRO data on typhoon-track forecast over the northwestern Pacific using the Global Forecast System of Taiwan's Central Weather Bureau (CWB). Their study showed that the assimilation of GPSRO can effectively reduce the track error for recurving typhoons, and the reduction in cross-track errors is more significant than along-track errors. However, for operational regional model systems, a systematic evaluation of the impact of GPSRO data on typhoon forecasts has not been reported.

Typhoon Weather Research and Forecasting (TWRF) is a typhoon forecast model, which has been in operation at CWB since 2010 and has been shown to possess good skills in typhoon forecasting (Hsiao et al., 2012). In this study, we perform a systematic evaluation of the impact of GPSRO data on typhoon-track forecast on 11 typhoons occurring over the northwestern Pacific between 2008 and 2010 using the TWRF modeling system.

\section{Experiment design}

The TWRF model is based on the Advanced Research core of the WRF (WRF-ARW) and has a horizontal resolution of $45 \mathrm{~km}$ with a $221 \times 127$ grid mesh (Fig. 1). It has 45 vertical layers, with the model top placed at $30 \mathrm{hPa}$. The analysis component of TWRF is the WRF-3DVAR data assimilation system; an incremental formulation is used to produce multivariate incremental analyses for surface pressure, wind, temperature, and relative humidity at the model grid points. The "cv5" background error covariance is used in this study that formulates the background error statistics in terms of physical-space control variables including stream function, unbalanced velocity potential, unbalanced surface pressure, unbalanced temperature, and "pseudo" relative humidity. With a $12 \mathrm{~h}$ partial cycling assimilation strategy (Hsiao et al., 2012), the analysis begins with a cold-start data assimilation using the NCEP Global Forecast System (GFS) analysis as the first guess, followed by two update cycles using the $6 \mathrm{~h}$ WRF forecasts from the previous cycle as the first guess. The physical parameterizations used by the TWRF model include the Goddard microphysics scheme (Tao et al., 2003), the Kain-Fritsch cumulus parameterization scheme (Kain and Fritsch, 1990), the Yonsei University (YSU) plan- 


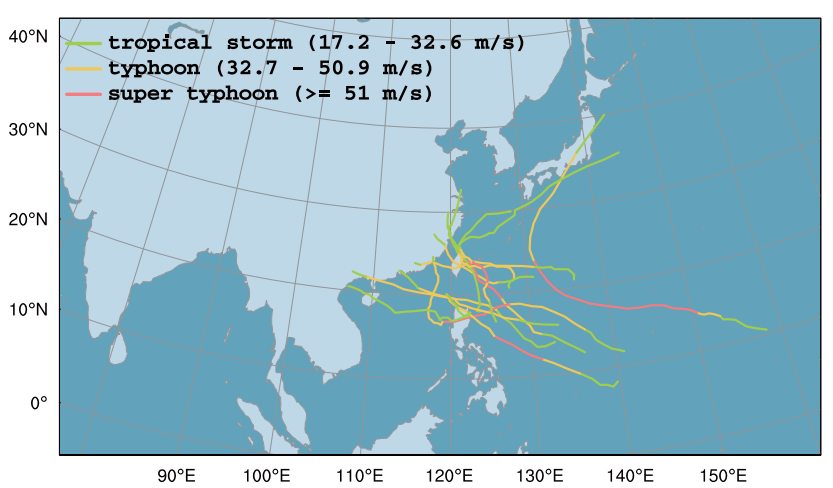

Figure 1. Domain of the TWRF and CWB best tracks of typhoons listed in Table 1. The curves indicate the track for each typhoon during its life cycle. Colors of different segments of each curve designate different stages of the corresponding storm.

etary boundary layer scheme (Hong et al., 2006), the Noah land surface model (Chen and Dudhia, 2001), and the Rapid Radiative Transfer Model (RRTM) longwave (Mlawer et al., 1997) and Goddard shortwave (Chou and Suarez, 1994) radiation schemes.

In this study, we assimilate GPSRO refractivity processed with CDAAC (COSMIC Data Analysis and Archive Center) (Kuo et al., 2004; Ho et al., 2009) software version 3.0 obtained from UCAR (University Corporation for Atmospheric Research) CDAAC, which is defined as

$N=77.6 \frac{P}{T}+3.73 \times 10^{5} \frac{e}{T^{2}}$,

where $P$ is the pressure $(\mathrm{hPa}), T$ is the temperature $(\mathrm{K})$, and $e$ is the partial pressure of water vapor in the air $(\mathrm{hPa})$ (Smith and Weintraub, 1953). With this local refractivity operator, the assimilation of GPSRO observations directly affects those fields that are related to mass (temperature, pressure, and water vapor), and indirectly affect the kinematic variables ( $u, v$ components of wind fields) through the background error covariance. In these data assimilation and forecast experiments, the typhoon center is relocated before each assimilation cycle, whereas the tropical cyclone (TC) bogus scheme is applied only at the cold start. The first set of experiments (Partial cycle With GPSRO - PWG) uses all available observation data; the second set (Partial cycle with No GPSRO - PNG) uses all other available data except GPSRO.

The primary factor affecting typhoon movement is the environmental steering flow (Galarneau and Davis, 2013). Over the northwestern Pacific, the circulation associated with the WPSH provides the primary environmental steering for typhoons. The internal circulation of a typhoon and its interaction with the environment also affect its motion. However, the steering of the environmental wind field is still the dominant factor. Therefore, in the subsequent discussion on the impact of the assimilation of GPSRO on typhoon forecasting
Table 1. List of typhoon cases between 2008 and 2010 over the western North Pacific Ocean.

\begin{tabular}{lll}
\hline Typhoon & Date-Time & Intensity \\
\hline Kalmaegi & 07/15/2008 06:00:00-07/19/2008 18:00:00 & typhoon \\
Fung-Wong & $07 / 25 / 2008$ 06:00:00-07/29/2008 06:00:00 & typhoon \\
Nuri & 08/18/2008 00:00:00-08/22/2008 18:00:00 & typhoon \\
Sinlaku & $09 / 08 / 2008$ 18:00:00-09/19/2008 18:00:00 & super typhoon \\
Hagupit & $09 / 19 / 2008$ 12:00:00-09/24/2008 06:00:00 & typhoon \\
Jangmi & $09 / 24 / 2008$ 12:00:00-09/28/2008 00:00:00 & super typhoon \\
Morakot & $08 / 03 / 200918: 00: 00-08 / 10 / 200912: 00: 00$ & typhoon \\
Parma & $09 / 29 / 2009$ 00:00:00-10/14/2009 06:00:00 & typhoon \\
Melor & $09 / 29 / 200912: 00: 00-10 / 08 / 200912: 00: 00$ & super typhoon \\
Fanapi & $09 / 15 / 201012: 00: 00-09 / 20 / 201012: 00: 00$ & typhoon \\
Megi & $10 / 13 / 201012: 00: 00-10 / 23 / 201000: 00: 00$ & typhoon \\
\hline
\end{tabular}

we will pay special attention to the impact on the environmental flow.

In this paper, we study 11 typhoon cases in the northwestern Pacific between 2008 and 2010 as listed in Table 1, for which the CWB issued typhoon warning and the storm intensity was stronger than the category of a tropical storm. Restricting to the period of 2008 to 2010 allows us to conduct this study with a relatively homogeneous experiment setting (a stable number of RO soundings, on changes in the assimilation system). For these cases, forecast experiments are initiated every $6 \mathrm{~h}$ within the time range given in Table 1 and the best track for each typhoon is shown in Fig. 1. The number of forecast cases for both PNG and PWG is 284, including 43 cases in which there are two typhoons within the model domain; therefore, the total number of typhoon cases for the statistics is 327 .

Before proceeding to the results section, it is important to confirm that the GPSRO data assimilation functions as expected. In Fig. 2 we show the statistics of observationbackground $(6 \mathrm{~h}$ forecast $)$ deviation $(\mathrm{OmB})$ and observationanalysis deviation $(\mathrm{OmA})$ averaged over all the cases. The results indicate that the background ( $6 \mathrm{~h}$ forecast) deviation (from observation) is significantly reduced following the assimilation of GPSRO data, both in terms of standard deviation and mean. It indicates that the WRF 3DVAR properly assimilates the $\mathrm{RO}$ refractivity observations.

\section{Results}

\subsection{Verification against ECMWF analysis}

In order to assess the impact of RO observations on the analysis and forecast of tropical cyclones, we verify the PNG and PWG grid-point fields against the ECMWF high-resolution analysis. The RMSE (root-mean-square error) of temperature $(T)$, water vapor mixing ratio $(Q)$, zonal wind $(U)$ and meridional wind $(V)$ are calculated.

Figure 3 shows the average difference in RMSE between PNG and PWG for various variables on each forecast day. A positive value means that the assimilation of GPSRO has a positive impact, if we regard the ECMWF high-resolution 


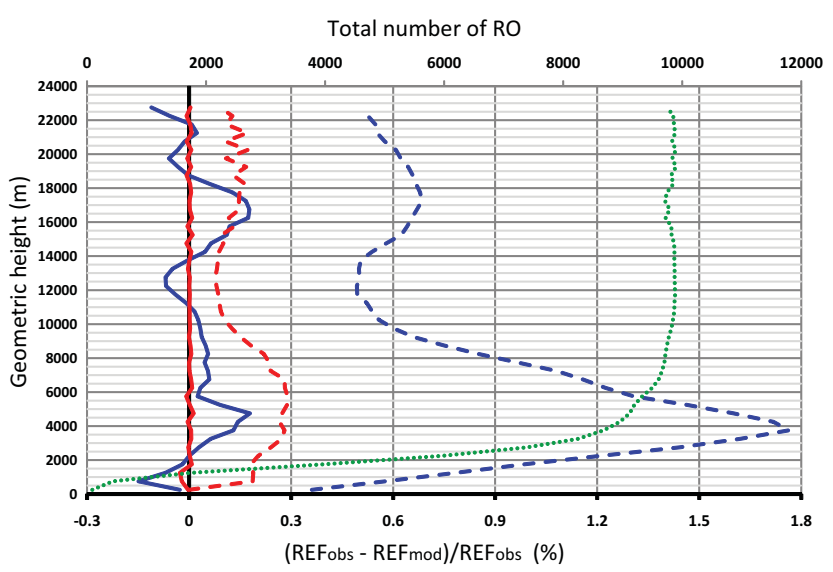

Figure 2. The solid lines are the observation-background ( $6 \mathrm{~h}$ forecast) deviation (OmB, blue) and observation-analysis deviation $(\mathrm{OmA}, \mathrm{red})$ and the dash line are their standard deviation (blue for $\mathrm{OmB}$ and red for OmA) averaged over all the cases. The green line represents the total number of assimilated RO soundings. The bottom horizontal axis gives the percentage, normalized by observation refractivity, and the top horizontal axis shows the number associated with the green line.

analysis as the "truth". From top to bottom, the four rows of figures are for $T, Q, U$, and $V$, respectively. Each row has four panels, from left to right, which show the results of $00,12,24,48$, and $72 \mathrm{~h}$ forecast. The vertical axis is pressure levels, and the horizontal axis is the difference in RMSE between PNG and PWG averaged over all cases. The blue line is the mean difference, and the area enclosed by the two pink lines surrounding the blue line represents the $95 \%$ confidence interval derived from the $T$ distribution (Student's $T$ test).

The significant positive impact of GPSRO observations on temperature analysis is quite apparent, and this impact increases with height. The impact is slightly negative below $400 \mathrm{hPa}$ for the analysis. As the forecast progresses, the positive impact at the upper level decreases with time. The slight negative impact below $400 \mathrm{hPa}$ at the initial analysis $(00 \mathrm{~h}$ forecast) becomes positive after 1 day. The contribution of GPSRO to the water vapor analysis is concentrated in the middle and lower levels, because the water vapor content is relatively low at high altitudes. In the lower troposphere the assimilation of GPSRO data gives a negative impact below $850 \mathrm{hPa}$, and remains negative for the first and second day. A significant positive impact in moisture is found between 700 and $200 \mathrm{hPa}$, with the largest impact at $700 \mathrm{hPa}$. By $72 \mathrm{~h}$, GPSRO assimilation gives a positive impact on moisture throughout the entire troposphere. We suspect that the slight negative impact of GPSRO assimilation below $850 \mathrm{hPa}$ may be affected by differences in data quality control between ECMWF and TWRF data assimilation systems. Also, moisture is the most challenging variable for models to analyze and predict. There may be considerable uncertainties in the ECMWF moisture analysis. We anticipate that further improvement in GPSRO data quality control may improve its use in the lower troposphere. For the $U$ wind field, GPSRO assimilation gives a significant positive impact only at upper levels (above $300 \mathrm{hPa}$ ). As forecast progresses, the positive impact on the $U$ wind gradually extends to the lower levels. By $72 \mathrm{~h}$, the $U$ wind component exhibits strong positive impact throughout the troposphere. The impact of GPSRO assimilation on the $V$ wind component behaves very similarly to that of the $U$ wind component. These results suggest that impacts of GPSRO on the analysis mainly occur at the upper levels. This implies that the TWRF model's short-range forecast (first guess for cycling assimilation) has larger uncertainty in upper levels, and the GPSRO can provide useful information to correct the first guess. The improved analysis at the upper levels then propagates to the lower levels, and improves the TWRF model forecast throughout the troposphere.

Through the local refractivity observation operator, the assimilation of GPSRO observations directly affects the analysis of the temperature and water vapor. Our experiments show that the GPSRO observations provide statistically significant positive contribution to water vapor analysis above $700 \mathrm{hPa}$ and temperature analysis above $500 \mathrm{hPa}$. The value of GPSRO observations for improving meteorological analysis in the upper troposphere and lower stratosphere is quite evident. The improvement in temperature analysis indirectly affects the analysis of the wind field through the background error covariance and the subsequent forecast through geostrophic adjustment. As a result, the wind field exhibits a similar behavior to that of the temperature field, i.e., a significant improvement in the low stratosphere initially, followed by positive impact throughout the troposphere, and the positive impact continues to increase with time through $72 \mathrm{~h}$ forecast. As will be shown later, the robust positive impact on the wind fields provides more accurate environmental steering flows, leading to improved track forecast.

\subsection{Impacts to typhoon-track errors}

Figure 4 shows the track error, verified against the CWB best track analysis, averaged over all 327 cases for 11 typhoons for PNG and PWG, respectively. The results show that the assimilation of GPSRO does not make a significant difference in typhoon-track error for the first $24 \mathrm{~h}$ forecast. However, after $36 \mathrm{~h}$, the difference becomes progressively larger with time, and the forecast track error of PWG is statistically significantly smaller than that of PNG by the end of $72 \mathrm{~h}$ forecast.

The difference in mean track error between PNG and PWG at the $72 \mathrm{~h}$ forecast is approximately $12 \mathrm{~km}$. Although this is only a modest improvement, it is statistically significant. In Fig. 5, the blue solid line shows the mean difference in track errors between PNG and PWG; a positive value indicates that, on average, the assimilation of GPSRO has a pos- 

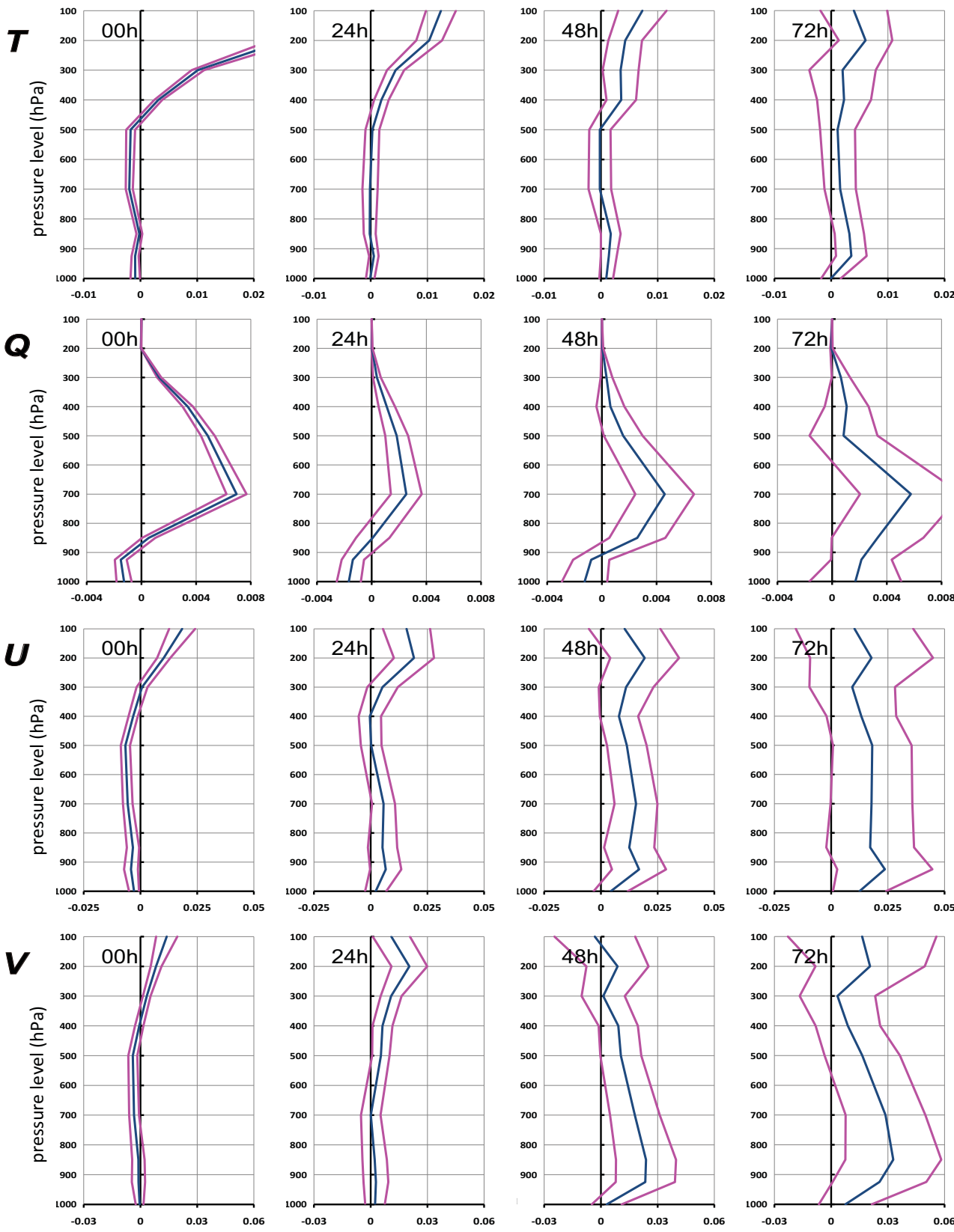

Figure 3. Mean difference in RMSE between PNG and PWG (blue line). From top to bottom: temperature ( $T$, unit: K), mixing ratio of water vapor $\left(Q\right.$, unit: $\left.\mathrm{kg} \mathrm{kg}^{-1}\right)$, zonal wind $\left(U\right.$, unit: $\left.\mathrm{ms}^{-1}\right)$ and meridional wind ( $V$, unit: $\left.\mathrm{m} \mathrm{s}^{-1}\right)$. The vertical axis is pressure level (unit: $\mathrm{hPa}$ ) and the area enclosed by the pink lines in each panel is the $95 \%$ confidence interval.

itive impact on forecast track error. The light blue area gives the $95 \%$ confidence interval of mean difference of track error derived from the Student's $T$ test. If the lower bound of the confidence interval is positive, then the positive impact of GPSRO assimilation is statistically significant. Figure 5 shows that the assimilation of the GPSRO observation has a positive impact on the initial analysis of the typhoon position, a neutral impact at $12 \mathrm{~h}$ forecast, and a slight positive impact between 24 to $36 \mathrm{~h}$ forecast. From $48 \mathrm{~h}$ forecast onward, the positive impact becomes increasingly more significant as the forecast progresses.

To gain further insights on the impact of GPSRO assimilation, we decompose the total track error into components that are along and perpendicular to the direction of the typhoon movement in the past $6 \mathrm{~h}$, respectively. The separation of these two components allows us to assess whether the impact on the forecast of the typhoon track is related primarily to the speed of the typhoon (indicated by along-track error) 


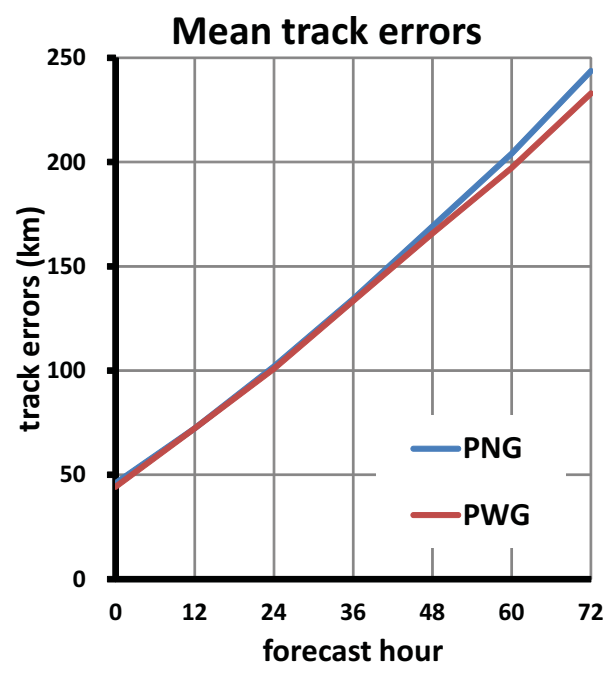

Figure 4. Mean track errors for PNG (blue line) and PWG (red line).

or the direction of the typhoon (indicated by cross-track error). The red columns and green columns of Fig. 5 illustrate the difference in along-track error and cross-track error between PNG and PWG, respectively. The assimilation of GPSRO contributes to a small increase in along-track error at the 12 and $36 \mathrm{~h}$ forecast. After $48 \mathrm{~h}$ forecast, GPSRO assimilation consistently reduces the along-track error. On the contrary, GPSRO assimilation reduces cross-track error throughout the entire $72 \mathrm{~h}$ forecast. The impact is the largest at $72 \mathrm{~h}$ forecast. As will be shown later, the large positive impact on cross-track error may be attributed to the improved analysis and prediction of environmental steering flow associated with WPSH.

\subsection{The importance of GPSRO data relative to radiosonde observations}

The routine radiosondes observations are available only at 00:00 and 12:00 UTC, and therefore, the relative importance of GPSRO observations on the analysis may vary, depending on the quantity of radiosonde observations. It would be interesting to assess the impact of GPSRO data with the 00:00/12:00 UTC analysis cycle versus that of 06:00/18:00 UTC analysis cycle. In our experiments, there are a total of 164 analysis cycles at 00:00/12:00 UTC and 163 analysis cycles at 06:00/18:00 UTC. On average, 7523 GPSRO observations are used at 00:00/12:00 UTC and 7376 GPSRO observations at 06:00/18:00 UTC, respectively. The variation in the amount of GPSRO observation at 00:00/12:00 UTC and 06:00/18:00 UTC is small, but the ratio of the amount of GPSRO and none-GPSRO data is $1: 6.12$ at 00:00/12:00 UTC vs. $1: 5.60$ at 06:00/18:00 UTC. This is likely to cause a variation in the impacts of GPSRO assimilation between 00:00/12:00 UTC and 06:00/18:00 UTC analysis-forecast cycles.

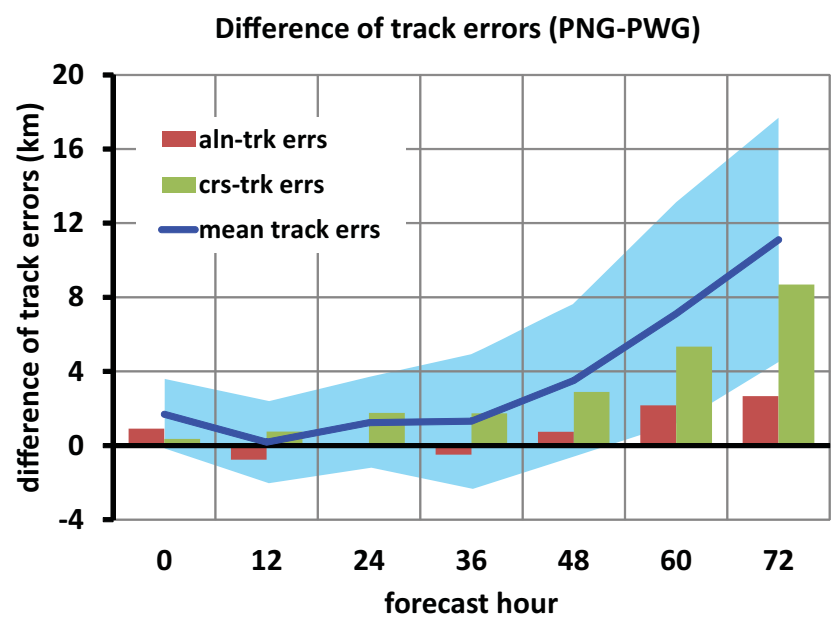

Figure 5. Difference between mean track errors, along-track errors and cross-track errors of PNG and PWG.

Figure 6 shows the impacts of GPSRO averaged over the $72 \mathrm{~h}$ forecast for 00:00/12:00 UTC and 06:00/18:00 UTC analysis cycle, respectively. The positive impacts of GPSRO on the temperature at upper levels are more pronounced for the 06:00/18:00 UTC cycle than the 00:00/12:00 UTC cycle. The maximum positive impact on the water vapor is at $700 \mathrm{hPa}$ for both cycles. However, the negative impact on water vapor at levels below $900 \mathrm{hPa}$ is also slightly larger for the 06:00/18:00 UTC cycle. For the wind field, the positive impact is generally greater for the 06:00/18:00 UTC except for the zonal wind at 400 to $300 \mathrm{hPa}$.

The greater positive impact for 06:00/18:00 UTC analysis cycle is also reflected in the typhoon-track forecasts. Figure 7 compares the impacts of GPSRO assimilation on the forecast typhoon-track error for 00:00/12:00 UTC (Fig. 7a) and 06:00/18:00 UTC (Fig. 7b) cycles, respectively. For the 00:00/12:00 UTC cycle, the impact of GPSRO is not significant until $72 \mathrm{~h}$ forecast, and only the $72 \mathrm{~h}$ forecast shows the positive impact with statistical significance (when the lower bound of vertical bar indicating $95 \%$ confidence is positive). On the other hand, the 06:00/18:00 UTC cycle gives statistically significant positive impact after $48 \mathrm{~h}$ forecast and the impact continues to increase with time.

As a matter of clarification, this comparison does not show the impact of GPSRO data relative to radiosonde observations, as even for the 06:00/18:00 UTC analysis-forecast cycles, radiosonde observations are used during the partial cycling assimilation. The results do suggest that the impact of GPSRO will likely be greater over regions where there is a lack of conventional sounding observations, such as the tropical oceans and the Southern Hemisphere. 
(a)
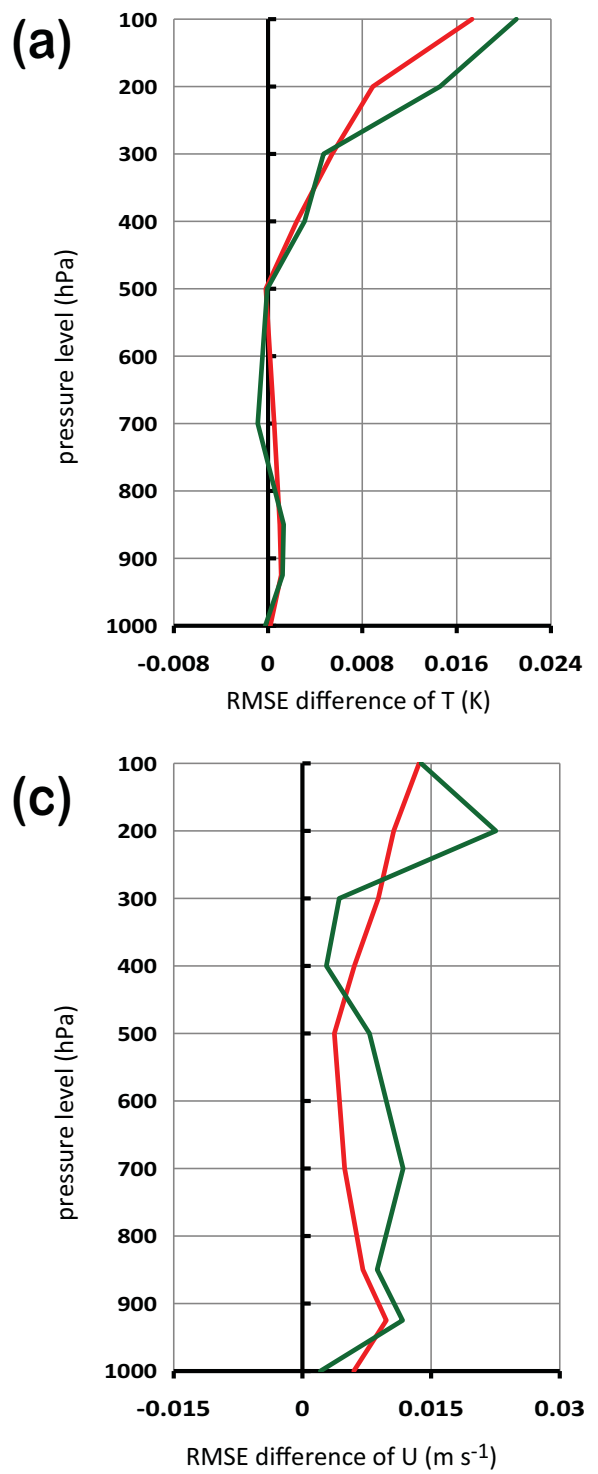

(b)

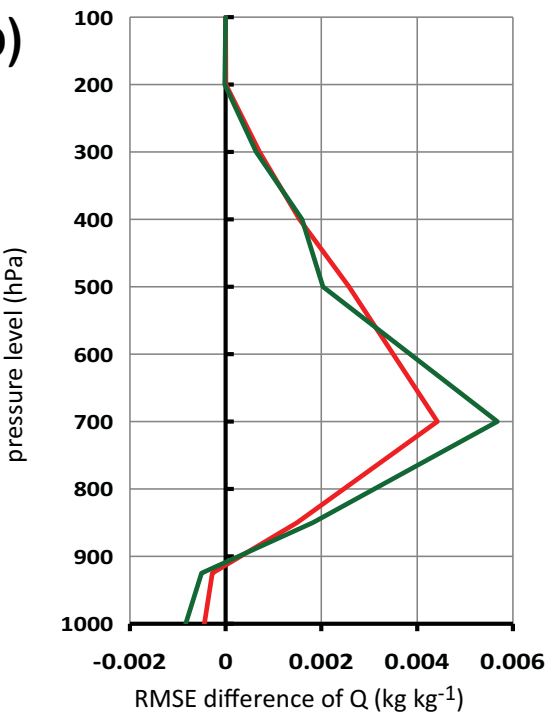

(d)

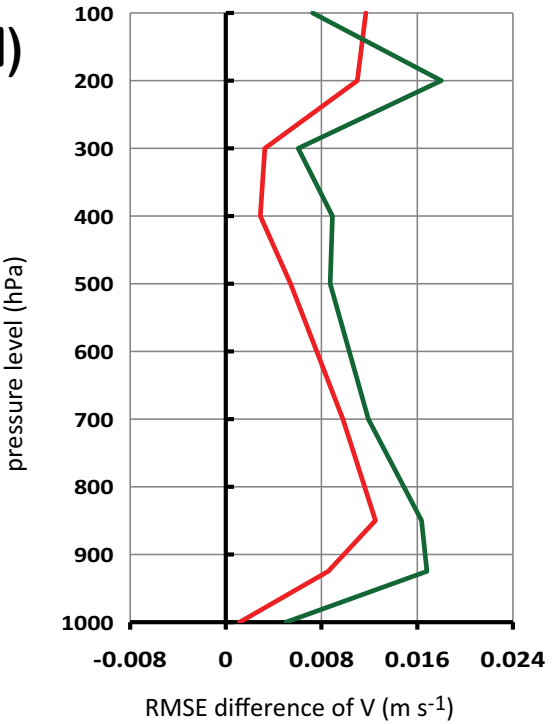

Figure 6. PNG-PWG difference of 00 to $72 \mathrm{~h}$ forecast average of RMSE for (a) temperature, (b) mixing ratio of water vapor, (c) zonal wind, and (d) meridional wind. The red line is the mean of 00:00/12:00 UTC cycles, the green line is the mean of 06:00/18:00 UTC cycles.

\subsection{Impacts on environmental steering flow}

As shown earlier, the assimilation of GPSRO improves the forecast of wind fields significantly. Moreover, most of the improvements in track forecast are associated with the reduction of cross-track error. It would be interesting to examine how GPSRO assimilation affects the synoptic-scale circulation, particularly, the environmental steering flow. For this purpose, we calculate the mean differences of wind fields at $500 \mathrm{hPa}$ between PWG and PNG, and apply a low pass filter with a wavelength of $1200 \mathrm{~km}$. The difference field (Fig. 8a) clearly shows an anti-cyclonic gyre over the northwestern Pacific Ocean. This indicates that the assimilation of GPSRO leads to the strengthening of the anti-cyclonic circulation of WPSH (Fig. 8b). The southwesterly flow on the western pe- riphery of WPSH becomes stronger, and will affect the crosstrack movement of the typhoons. Most likely, the model error is responsible for the weakening of WPSH. Through the assimilation of GPSRO, the strength of WPSH is partially restored.

To illustrate the impact of GPSRO assimilation on the prediction of synoptic-scale circulation, we show in Fig. 9 the difference in wind fields between PWG and PNG (PWGPNG) (left column; a, c, e and g), and the errors of PNG forecasts verified against ECMWF analysis (ECMWF-PNG) (right column; b, d, f and h) for $00 \mathrm{~h}(\mathrm{a}, \mathrm{b}), 24 \mathrm{~h}(\mathrm{c}, \mathrm{d}), 48 \mathrm{~h}$ $(\mathrm{e}, \mathrm{f})$ and $72 \mathrm{~h}(\mathrm{~g}, \mathrm{~h})$ forecasts at $700 \mathrm{hPa}$. The shading shows the wind speed and the vector gives the wind direction. If the ECMWF-PNG and PWG-PNG have a similar pattern, it im- 

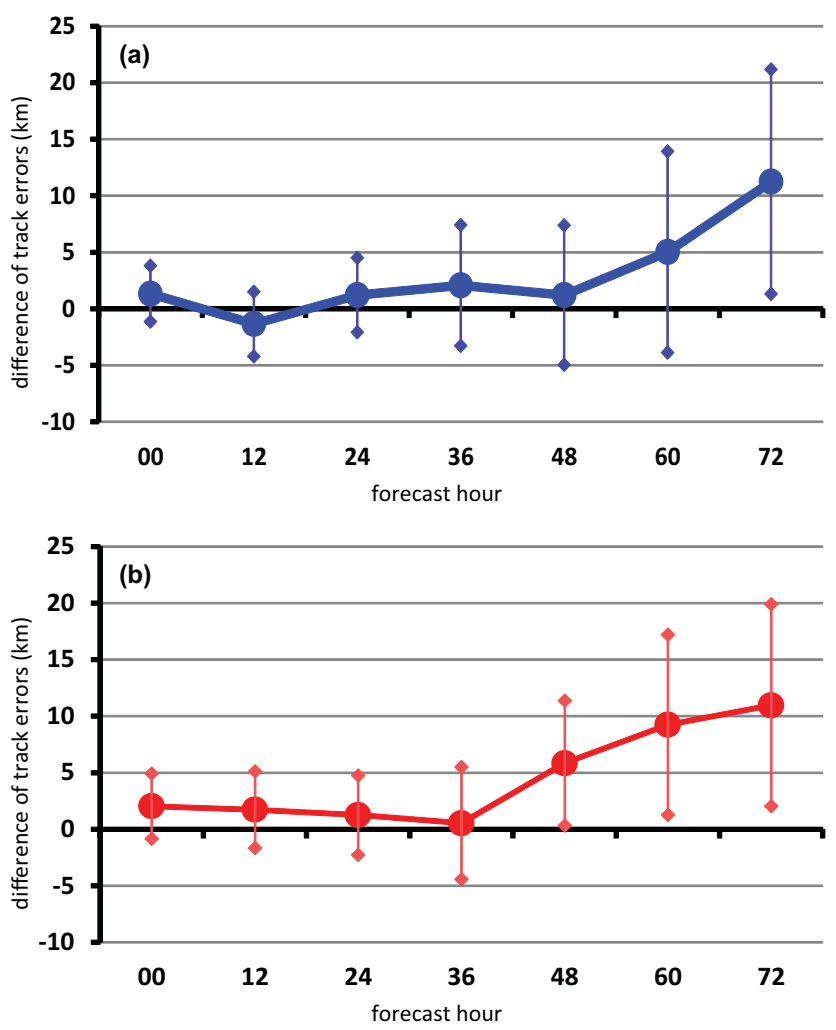

Figure 7. Difference between mean track errors of PNG and PWG for initial hour (a) 00:00/12:00 and (b) 06:00/18:00.

plies that the forecast of PWG is closer to ECMWF analysis than PNG does. The ECMWF-PNG difference wind fields (right column of Fig. 9) show an anti-cyclonic gyre on the western periphery of the WPSH (east of Taiwan) at the $00 \mathrm{~h}$, and the difference wind speed on the south and west edge of WPSH becomes progressively stronger with time. This suggests that WPSH as predicted by PNG is weaker than the ECMWF analysis (Fig. 8b). The PWG-PNG (left column of Fig. 9) difference wind fields give a pattern very similar to that of ECMWF-PNG, and the wind speed of PWG in the area southeast of Taiwan is also larger than PNG after $48 \mathrm{~h}$ forecast. Although the area with anti-cyclonic wind difference from PWG-PNG is smaller than that of ECMWF-PNG, its location is very close to that of ECMWF-PNG. The area to the southeast of Taiwan is particularly important, as this is the region where most of the typhoons in this study pass though (Fig. 1). It is clear that the assimilation of GPSRO refractivity improves the forecast of synoptic-scale circulation, which in turn leads to improved typhoon-track forecasts.

The motion of typhoons is largely dictated by the environmental steering flow and the beta effect of the intrinsic dynamics of typhoon circulation. For the majority of typhoon cases, the environmental steering flow is the dominating factor. The steering flow is often represented by the deep layer mean (from 1000 to $200 \mathrm{hPa}$ ) of the averaged asymmetrical wind inside the typhoon circulation. To assess the impact of
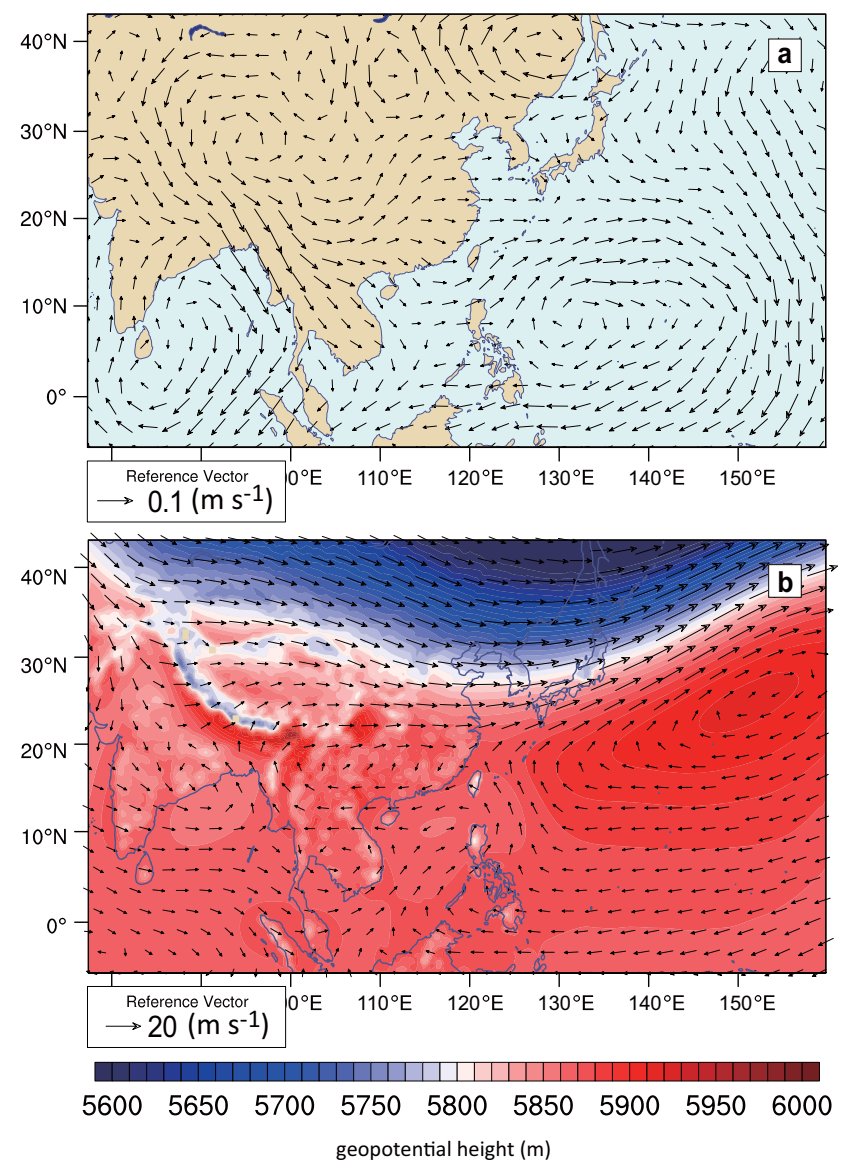

Figure 8. (a) Mean differences of analysis wind field at $500 \mathrm{hPa}$ between PWG and PNG and (b) the mean of wind (vector) and geopotential height (shading) of PNG at $500 \mathrm{hPa}$.

GPSRO data assimilation on the prediction of steering flow, we compare the respective absolute error in steering flow between PWG and PNG (verified against the steering flow calculated from the ECMWF analysis). We define the difference between the two such that a positive difference indicates that the assimilation of GPSRO has a positive impact on the steering flow. Figure 10a shows that there is no clear systematic difference in the speed of the steering flow. However, for the direction of the steering flow, the assimilation of GPSRO clearly has a positive impact throughout the $72 \mathrm{~h}$ forecast, except for the $24 \mathrm{~h}$ forecast. This is consistent with the results, shown in Fig. 5, that the improvement in typhoon-track forecast is mainly associated with the reduction of cross-track error.

For the 11 typhoon cases examined in this study, they occur in the southwestern periphery of WPSH, and most of them move from southeast to northwest. Figure 11 shows the mean position bias for the forecast typhoon center in zonal direction ( $x$ axis) and meridional direction ( $y$ axis). Most of the predicted typhoons are located to the northeast of the observed position, and move increasingly eastward relative to 

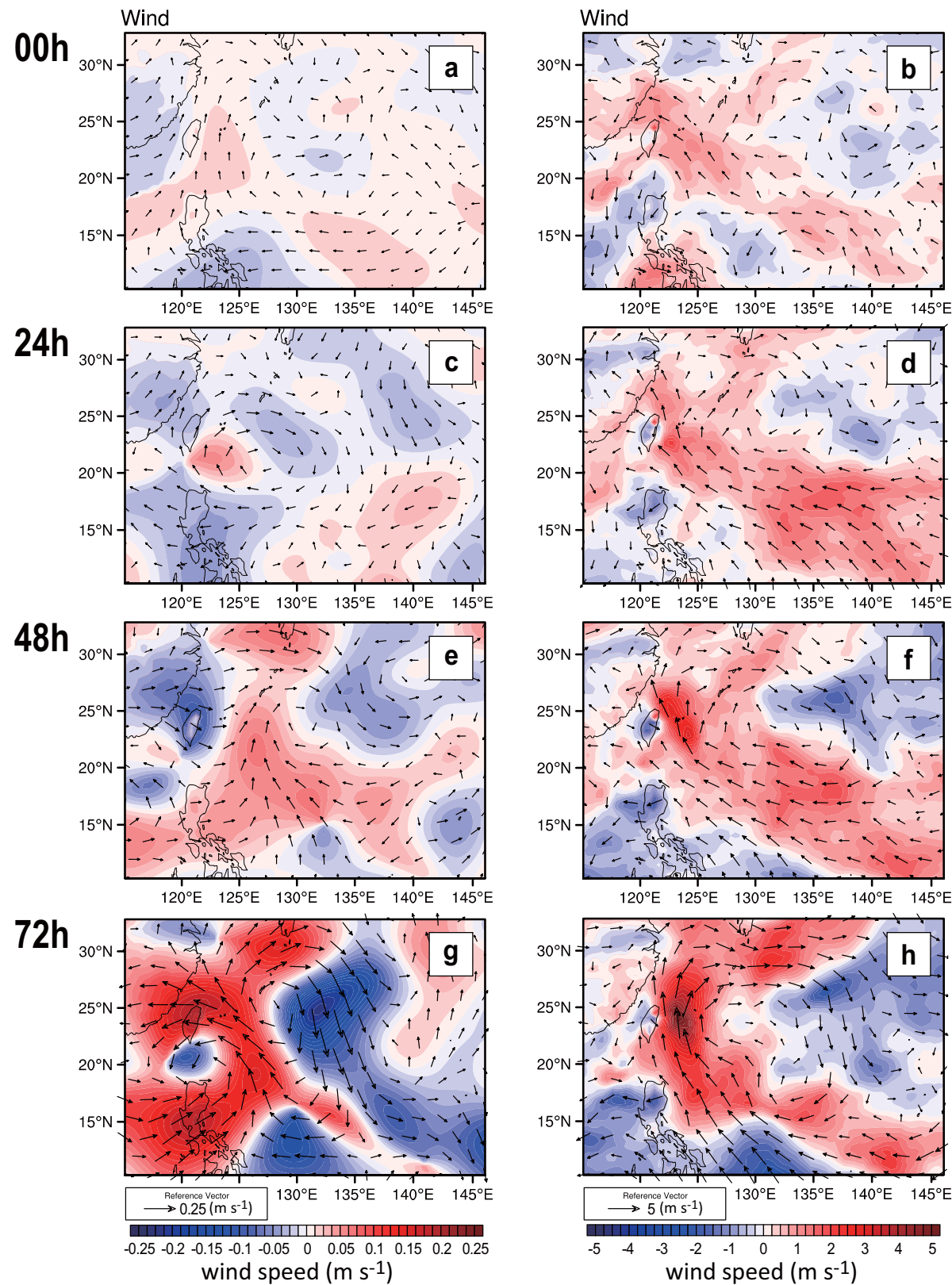

Figure 9. Mean differences of wind speed (shading) and wind vectors at $700 \mathrm{hPa}$ between PWG and PNG (left column), and between ECMWF and PNG (right column) at forecast time from 00 to $72 \mathrm{~h}$.

the observation location as forecast progresses. This implies that the speed for predicted typhoon motion is systematically too slow both in PWG and PNG. However, the assimilation of GPSRO extends the WPSH southward and westward, and improving the prediction of the direction of steering flow. As a result, the northward and eastward systematic position bias is reduced.

\section{Summary and conclusions}

In this study, we perform a systematic evaluation of the impacts of GPSRO on typhoon-track forecast. The operational typhoon forecast model, TWRF, of Taiwan's CWB is used to study 11 typhoon cases that occurred in the northwestern Pacific between 2008 and 2010. The results show that the assimilation of GPSRO reduces the forecast track error after $36 \mathrm{~h}$ forecast, and the track error at $72 \mathrm{~h}$ forecast is reduced by $\sim 12 \mathrm{~km}(5 \%)$. Although this reduction in the track error is very modest, it is statistically significant. Most of the improvement in track forecast is associated with the reduction of cross-track error. In our opinion, the $\sim 12 \mathrm{~km}$ improvement on $72 \mathrm{~h}$ typhoon-track forecast is robust, despite of uncertainties in best track estimated by Landsea and Franklin 
(a) Diff. of steering speed

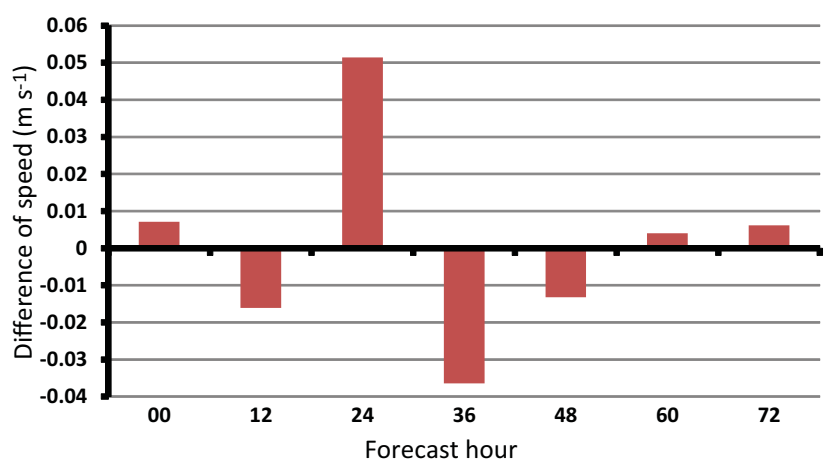

(b) Diff. of steering direction

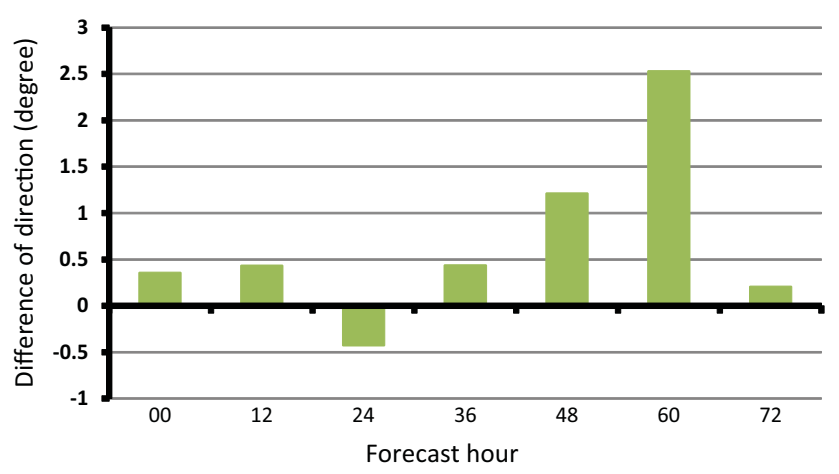

Figure 10. Difference of absolute error (against the steering flow derived from analysis of ECMWF) on steering flow (a) speed and (b) direction between PNG and PWG.

(2013) for the following reasons. (a) The best track position errors may be large for an individual case at a specific time. However, the position errors are random and the mean position error would be close to 0 when averaged over 300 cases. (b) With "vortex relocation", the storms in both PNG and PWG are placed at the same position (based on best track) initially. Therefore, the best track uncertainty does not favor one experiment versus the other. (c) The mean $72 \mathrm{~h}$ forecast track error of PWG is $234 \mathrm{~km}$, which is significantly largely than the best track uncertainty. As stated by Landsea and Franklin (2013), the best track uncertainty should not pose a problem for assessing improvement on a 3-day track forecast. (d) The Student's $T$ test has demonstrated that the impact of GPSRO assimilation on typhoon-track forecast is statistically significant. (e) Our subsequent analysis of the results demonstrate that the improvement due to GPSRO assimilation can be attributed to improved prediction of WPSH and the steering flow. Therefore, there is solid physical explanation supporting the robustness of the impact of GPSRO assimilation on typhoon-track forecast.

Further analysis shows that the assimilation of GPSRO data improves the analysis and prediction of the WPSH, such that it is further extended westward and southward, consistent with the ECMWF analysis. The wind fields over the

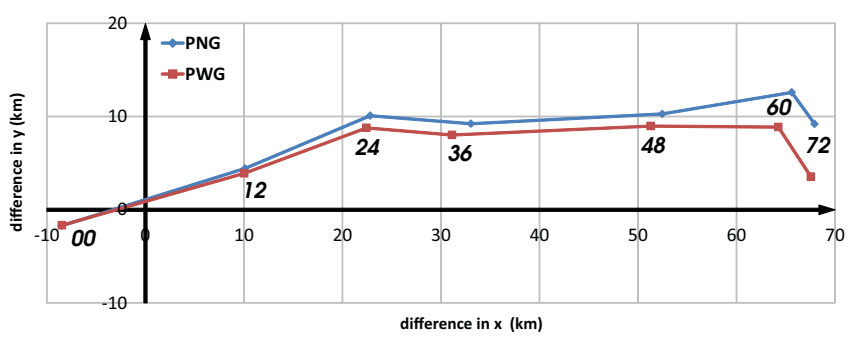

Figure 11. Mean track bias in longitude ( $x$ axis) and latitude ( $y$ axis) direction.

southwestern periphery of WPSH are improved as a result of GPSRO data assimilation. The improved environmental steering flow associated with the WPSH, in turn, leads to improved track forecast.

Although the assimilation of GPSRO data only produces a very modest improvement in track forecast, these results are very encouraging, given the relatively small number of GPSRO soundings assimilated and the limitations of the current experiment framework. With a $12 \mathrm{~h}$ partial cycling analysis, only about 100 GPSRO soundings are used over a domain of $9945 \mathrm{~km} \times 5670 \mathrm{~km}$. Most data impact studies using a global model are performed with a fully cycling analysis over a period of at least 2 weeks. This would allow a significantly larger amount of data being assimilated. Also, the impact of the data is allowed to accumulate with time. With a fresh cold start of each cycle for a partial cycling strategy, there is no accumulation of the impact of GPSRO. The TWRF has a horizontal resolution of $45 \mathrm{~km}$, which cannot properly capture the mesoscale circulation of a tropical cyclone. Also the assimilation of GPSRO data using a 3DVar system with a simple local refractivity operator is suboptimal. The FORMOSAT-7/COSMIC-2, which is expected to be launched in May 2016, will provide an order of magnitude increase in GPSRO soundings over the tropics. The assimilation of FORMOSAT-7/COSMIC-2 using an advanced data assimilation system with a sophisticated observation operator and a high-resolution mesoscale model is expected to produce a significant improvement in typhoon prediction both in terms of track and intensity.

Acknowledgements. This study was supported by National Space Organization (NSPO) in Taiwan. The computational resources were partly provided by the National Center for High-performance Computing (NCHC) in Taiwan. In addition, we acknowledge the Atmospheric Research Data Bank at the Taiwan Typhoon and Flood Research Institute for supplying the atmospheric research data. Y.-H. Kuo acknowledges the support of NOAA Hurricane Forecast Improvement Project (HFIP) through the Developmental Testbed Center (DTC).

Edited by: A. K. Steiner 


\section{References}

Anthes, R. A., Ector, D., Hunt, D. C., Kuo, Y.-H., Rocken, C., Schreiner, W. S., Sokolovskiy, S. V., Syndergaard, S., Wee, T.K., Zeng, Z., Bernhardt, P. A., Dymond, K. F., Chen, Y., Liu, H., Manning, K., Randel, W. J., Trenberth, K. E., Cucurull, L., Healy, S. B., Ho, S.-P., McCormic, C., Meehan, T. K., Thompson, D. C., and Yen, N. L.: The COSMIC/FORMOSAT-3 mission: Early results, B. Am. Meteorol. Soc., 89, 313-333, 2008.

Aparicio, J. M., Deblonde, G., Garand, L., and Laroche, S.: The signature of the atmospheric compressibility factor in COSMIC, CHAMP and GRACE radio occultation data, J. Geophys. Res., 114, D16144, doi:10.1029/2008JD011156, 2009.

Buontempo, C., Jupp, A., and Rennie, M. P.: Operational NWP assimilation of GPS radio occultation data, Atmos. Sci. Lett., 9, 129-133, 2008.

Chen, F. and Dudhia, J.: Coupling an advanced land surfacehydrology model with the Penn State-NCAR MM5 modeling system. Part I: Model implementation and sensitivity, Mon. Weather Rev., 129, 569-585, 2001.

Cucurull, L. and Derber, J. C.: Operational implementation of COSMIC observations into NCEP's global data assimilation system, Weather Forecast., 23, 702-711, 2008.

Cucurull, L., Derber, J. C., Treadon, R., and Purser, R. J.: Assimilation of Global Positioning System Radio Occultation Observations into NCEP's Global Data Assimilation System, Mon. Weather Rev., 135, 3174-3193, 2007.

Galarneau, T. J. and Davis, C. A.: Diagnosing forecast errors in tropical cyclone motion, Mon. Weather Rev., 141, 405-430, 2013.

Hajj, G. A., Ao, C. O., Iijima, B. A., Kuang, D., Kursinski, E. R., Mannucci, A. J., Meehan, T. K., Romans, L. J., Juarez, M. de la Torre, and Yunck, T. P.: CHAMP and SAC-C atmospheric occultation results and intercomparisons, J. Geophys. Res., 109, D06109, doi:10.1029/2003JD003909, 2004.

Healy, S. B.: Forecast impact experiment with a constellation of GPS radio occultation receivers, Atmos. Sci. Lett., 9, 111-118, 2008.

Ho, S.-P., Kerchengast, G., Leroy, S., Wickert, J., Mannucci, A. J., Steiner, A., Hunt, D., Schreiner, W., Sokolovskiy, S., Ao, C., Borsche, M., von Engeln, A., Foelsche, U., Heise, S., Iijima, B., Kuo, Y.-H., Kursinski, R., Pirscher, B., Ringer, M., Rocken, C., and Schmidt, T.: Estimating the uncertainty of using GPS radio occultation data for climate monitoring: Intercomparison of CHAMP refractivity climate records from 2002 to 2006 from different data centers, J. Geophys. Res., 114, D23107, doi:10.1029/2009JD011969, 2009.

Hong, S.-Y., Noh, Y., and Dudhia, J.: A new vertical diffusion package with an explicit treatment of entrainment processes, Mon. Weather Rev., 134, 2318-2341, 2006.

Hsiao, L.-F., Chen, D.-S., Kuo, Y.-H., Guo, Y.-R., Yeh, T.-C., Hong, J.-S., Fong, C.-T., and Lee, C.-S.: Application of WRF 3DVAR to operational typhoon prediction in Taiwan: impact of outer loop and partial cycling approaches, Weather Forecast., 27, 12491263, 2012.

Huang, C.-Y., Kuo, Y.-H., and Chen, S.-H.: Improvements on Typhoon Forecast with Assimilated GPS Occultation Refractivity, Weather Forecast., 20, 931-953, 2005.
Kain, J. S. and Fritsch, J. M.: A one-dimensional entraining/detraining plume model and its application in convective parameterization, J. Atmos. Sci., 47, 2784-2802, 1990.

Kueh, M.-T., Huang, C.-Y., Chen, S.-Y., Chen, S.-H., and Wang, C.-J.: Impact of GPS radio occultation soundings on prediction of Typhoon Bilis (2006) landfalling Taiwan, Terr. Atmos. Ocean Sci., 20, 115-131, 2009,

http://www.ocean-sci.net/20/115/2009/.

Kuo, Y.-H., Zou, X., and Huang, W.: The impact of Global Positioning System data on the prediction of an extratropical cyclone: An observing system simulation experiment, Dynam. Atmos. Oceans, 27, 439-470, 1997.

Kuo, Y.-H., Wee, T.-K., Sokolovskiy, S., Rocken, C., Schreiner, W., Hunt, D., and Anthes, R. A.: Inversion and error estimation of GPS radio occultation data, J. Meteorol. Soc. Jpn., 82, 507-531, 2004.

Kuo, Y.-H., Liu, H., Guo, Y.-R., Terng, C.-T., and Lin. Y.-T.: Impact of FORMOSAT-3/COSMIC data on typhoon and Mei-yu prediction, in: Recent Progress in Atmospheric Sciences: Applications to the Asia-Pacific Region, World Scientific, 458-483, 2009.

Kursinski, E. R., Hajj, G. A., Hardy, K. R., Schofield, J. T., and Linfield, R.: Observing Earth's atmosphere with radio occultation measurements, J. Geophys. Res., 102, 23429-23465, 1997.

Landsea, C. W. and Franklin, J. L.: Atlantic Hurricane Database Uncertainty and Presentation of a New Dataset Format, Mon. Weather Rev., 141, 3576-3592, 2013.

Larsen, G. B., Lauritsen, K. B., Rubek, F., and Sorensen, M. B.: GRAS-SAF Radio Occultation Data from EPS/Metop, in: Occultation for Probing Atmosphere and Climate, Kirchengast, G., Foelsche, U., and Steiner, A. K., Springer, 111-118, 2004.

Liu, H., Anderson, J., and Kuo, Y.-H.: Improved Analyses and Forecasts of Hurricane Ernesto's Genesis Using Radio Occultation Data in an Ensemble Filter Assimilation System, Mon. Weather Rev., 140, 151-166, 2012.

Mlawer, E. J., Taubman, S. J., Brown, P. D., Iacono, M. J., and Clough, S. A.: Radiative transfer for inhomogeneous atmospheres: RRTM, a validated correlated-k model for the longwave, J. Geophys. Res., 102, 16663-16682, 1997.

Poli, P., Healy, S. B., and Dee, D. P.: Assimilation of Global Positioning System radio occultation data in the ECMWF ERAInterim reanalysis, Q. J. Roy. Meteor. Soc., 136, 1972-1990, doi:10.1002/qj.722, 2010.

Shen, Y.-C., Chen, Y.-C., Yang, M.-J., Fong, C.-T., and Chen, W.M.: The Impacts of GPSRO data to the forecast typhoon tracks in Central Weather Bureau's Global Forecast System, 2011 Conference on Weather Analysis, Forecasting and Seismic Observation, Taipei, Taiwan, 20-22 September 2011, 90-93, 2011 (in Chinese)

Smith, E. K. and Weintraub, S.: The constants in the equation for atmospheric refractive index at radio frequencies, P. IRE, 41, 1035-1037, 1953.

Tao, W.-K., Simpson, J., Baker, D., Braun, S., Chou, M.-D., Ferrier, B., Johnson, D., Khain, A., Lang, S., Lynn, B., Shie, C.-L., Starr, D., Sui, C.-H., Wang, Y., and Wetzel, P.: Microphysics, radiation and surface processes in the Goddard Cumulus Ensemble (GCE) model, Meteorol. Atmos. Phys., 82, 97-137, 2003.

Ware, R., Rocken, C., Solheim, F., Exner, M., Schreiner, W., Anthes, R., Feng, D., Herman, B., Gorbunov, M., Sokolovskiy, S., Hardy, K., Kuo, Y., Zou, X., Trenberth, K., Meehan, T., Mel- 
bourne, W., and Businger, S.: GPS soundings of the atmosphere from low earth orbit: Preliminary results, B. Am. Meteorol. Soc., 77, 19-40, 1996.

Wickert, J., Reigber, C., Beyerle, G., König, R., Marquardt, C., Schmidt, T., Grunwaldt, L., Galas, R., Meehan, T. K., and Melbourne, W. G.: Atmosphere sounding by GPS radio occultation: First results from CHAMP, Geophys. Res. Lett., 28, 3263-3266, 2001.
Wickert, J., Arras, C., Ao, C. O., Beyerle, G., Falck, C., Grunwaldt, L., Healy, S. B., Heise, S., Helm, A., Huang, C.-Y., Jakowski, N., Konig, R., Mannucci, T., Mayer, C., Michalak, G., Poli, P., Rothacher, M., Schmidt, T., Stosius, R., and Tapley, B.: CHAMP, GRACE, SAC-C, TerraSAR-X/TanDEM-X: Science results, status and future prospects, GRAS SAF Workshop on Applications of GPSRO Measurements, ECMWF, 16-18 June 2008, 43-52, 2008. 